\title{
Infection with Leishmania major induces interleukin-12 production in vivo
}

\author{
Leda Q. Vieira ${ }^{\mathrm{a}}$, Brian D. Hondowicz ${ }^{\mathrm{a}}$, Luis C.C. Afonso ${ }^{\mathrm{a}}$, Maria Wysocka ${ }^{\mathrm{b}}$, Giorgio \\ Trinchieri ${ }^{\mathrm{b}}$ and Phillip Scott ${ }^{\mathrm{a},{ }^{*}}$ \\ ${ }^{a}$ Department of Pathobiology, School of Veterinary Medicine, University of Pennsylvania, 3800 Spruce Street, Philadelphia, PA 19104, USA, \\ and ${ }^{b}$ The Wistar Institute of Anatomy and Biology, 36th and Spruce Streets, Philadelphia, PA 19104, USA
}

(Received 28 March 1994; accepted 30 March 1994)

\section{Summary}

Experimental infections of mice with the protozoan parasite Leishmania major provide an excellent model for defining the conditions required for generation of $\mathrm{CD} 4^{+} \mathrm{Th} 1$ and $\mathrm{Th} 2$ cells in vivo. Since interleukin-12 (IL-12) has been implicated in the development of Th1 cells, we investigated whether $L$. major stimulates IL-12 production in vitro or in vivo. Surprisingly, macrophages cultured in vitro failed to produce IL-12 following $L$. major infection. In contrast, lymph node cells from $\mathrm{C} 3 \mathrm{H}$ mice infected for 2 days with $L$. major produced elevated levels of IL-12. In order to determine if the inability to stimulate IL-12 production was limited to in vitro infections, we infected macrophages in vivo by inoculating $L$. major into the peritoneal cavity. Peritoneal cells isolated $24 \mathrm{~h}$ later exhibited a significant increase in the number of cells producing IL-12. In addition, supernatants harvested from these cells following culture contained elevated levels of IL-12. These data indicate that $L$. major infection induces increased IL-12 production in mice.

\section{Introduction}

Interleukin-12 (IL-12) is produced by macrophages and enhances cytotoxicity and interferongamma $(\mathrm{IFN} \gamma)$ production by $\mathrm{T}$ and natural killer

Key words: Th subset; Th1 cell; Leishmania major; Interleukin-12; Macrophage

*Corresponding author: Dr. Phillip Scott, Department of Pathobiology, School of Veterinary Medicine, University of Pennsylvania, 3800 Spruce Street, Philadelphia, PA 19104, USA.
(NK) cells [1,2]. Recently it has been implicated as a critical cytokine in the development of Th1 cells both in vitro and in vivo [3-5]. Since we previously found that $L$. major infection in the resistant $\mathrm{C} 3 \mathrm{H}$ mouse strain is associated with an early NK cell cytotoxic response, the production of IFN $\gamma$, early development of a CD4 + Th1 response, and early control of the parasites [6], we postulated that IL-12 might play a critical role in the immune response to this infection.

IL-12 is a heterodimeric cytokine. The mRNA for one chain of IL-12, p35, is constitutively produced by several cell types. Gene expression of the other chain, $\mathrm{p} 40$, is up-regulated in macrophages, and possibly other cell types such as B cells and neutrophils, following exposure to certain pathogens or their products [7]. To date, only the heterodimer has been found to have biological activity, although the presence of p 40 correlates with increased levels of the heterodimer [7]. In the present study, we measured the levels of p40 as well as the presence of biologically active IL-12 in supernatants from cells that were infected in vivo or in vitro. We found that $L$. major induces the production of both $\mathrm{p} 40$ and biologically active IL-12, but only when cells are infected in vivo. These data suggest that in vitro infection does not accurately mimic the events that are occurring in vivo.

\section{Materials and Methods}

\subsection{Mice}

Female $\mathrm{C} 3 \mathrm{HeB} / \mathrm{FeJ}$ mice of $6-8$ weeks of age were purchased from Jackson Laboratories and maintained in a specific pathogen-free facility. 


\subsection{Parasites and infection}

L. major WHO MHOM/IL/80/Friedlin was maintained in Grace's insect tissue culture medium (Gibco, Grand Island, NY) with $20 \%$ fetal bovine serum and $2 \mathrm{mM}$ glutamine. In all experiments, stationary phase promastigotes were harvested and the metacyclic forms were selected using Arachis hypogaea agglutinin (Sigma, St. Louis, MO). Mice were infected in the hind footpad with $2 \times 10^{6}$ metacyclic promastigotes, or intraperitoneally with $5 \times 10^{7}$ parasites. Staphylococcus aureus Cowan I strain (SAC) (Pansorbin; Calbiochem-Behring, La Jolla, CA), Corynebacterium parvum (Trudeau Institute, Saranac Lake, NY), and Listeria monocytogenes (strain 104035; generously provided by Dr. Daniel Portnoy, University of Pennsylvania School of Medicine) were used to stimulate macrophages in vitro. $L$. monocytogenes was heat-killed for $60 \mathrm{~min}$ at $60^{\circ} \mathrm{C}$ (HKLM).

\subsection{Cytokine assays}

IL-12 (p40) was measured in a 2-site ELISA using a pair of monoclonal antibodies $(\mathrm{mAb})$ that recognize murine p40. Biologically active IL-12 was measured by a capture assay with a mAb directed against murine $\mathrm{p} 40$ bound to a 96 -well plate. $\mathrm{C} 3 \mathrm{H}$ spleen cells were added to these wells and incubated for $48 \mathrm{~h}$ after which IFN $\gamma$ levels were measured. Values were derived from a standard curve performed with recombinant murine IL-12 (Genetics Institute, Cambridge, MA). The p40 ELISPOT assay was adapted from Morris et al. [8]. Briefly, monoclonal anti-murine $\mathrm{p} 40$ was bound to a 96-well plate. Peritoneal cells were added to the wells at various concentrations and incubated for $3 \mathrm{~h}$, after which the plates were washed, and a biotinylated anti$\mathrm{p} 40$ antibody added. After $1 \mathrm{~h}$ incubation, the plates were washed and alkaline phosphatase-streptavadin added. After $30 \mathrm{~min}$, the substrate was added in agarose, and the plates were left to develop overnight. The number of spots were counted by visual examination on a dissecting microscope.

\subsection{Macrophage cultures}

Peritoneal exudate cells were harvested 5 days after injection of $2 \mathrm{ml}$ of thioglycollate. Macrophages $\left(1 \times 10^{6}\right)$ were incubated in 24-well plates for $18 \mathrm{~h}$, after which the non-adherent cells were removed and bacteria or $L$. major promastigotes were added at various concentrations. After $24 \mathrm{~h}$ supernatants were collected, and the levels of p40 and IL-12 measured.

\subsection{Statistical analysis}

Each experiment was repeated at least 3 times. Significant differences between groups have been determined by Student's $t$ test.

\section{Results and Discussion}

In order to determine if metacyclic promastigotes induce IL-12 production following infection of $\mathrm{C} 3 \mathrm{H}$ mice, we measured $\mathrm{p} 40$ levels in supernatants taken from cultures of lymph node cells harvested 2 days after infection. The production of p40 was significantly higher by cells from infected mice when compared with normal animals, ranging from a 2- to 70fold increase (Table 1). This increase correlated with our previously reported findings that within the first 2 days of infection there is increased IFN $\gamma$ production and a significant NK cell cytotoxic response by lymph node cells [6]. These data indicate that L. major can induce 440 production in vivo. Since macrophages are the host cell of $L$. major, and also produce IL-12, they would be the likely candidate for the in vivo source of IL-12. To test this possibility directly, macrophages were harvested from the peritoneal cavity of $\mathrm{C} 3 \mathrm{H}$ mice and cultured in 24-well plates. $S$. aureus Cowan strain I (SAC), C. parvum, L. monocytogenes (HKLM) or metacyclic L. major promastigotes were added to the macrophages, and supernatants harvested $24 \mathrm{~h}$ later. Different concentrations of each pathogen were added to the macrophages; only the data for the concentration that induced optimal IL-12 production are shown (Fig. 1). Increased levels of both $\mathrm{p} 40$ and biologically active IL-12 were present in supernatants from macrophages incubated with all of the bacteria. In contrast, when metacyclic promastigotes were added to the macrophages, no

TABLE 1

IL-12 (p40) PRODUCTION BY LYMPH NODE CELLS TAKEN FROM C3H MICE INFECTED FOR TWO DAYS WITH L. MAJOR

\begin{tabular}{lll}
\hline Experiment No. & \multicolumn{2}{l}{$40(\mathrm{pg} / \mathrm{ml})$} \\
\cline { 2 - 3 } & Control mice & Infected mice \\
\hline 1 & 418 & 1123 \\
2 & 270 & 3000 \\
3 & 110 & 1280 \\
4 & 62 & 4380 \\
mean & 215 & $2446^{*}$ \\
standard deviation & 161 & 1544 \\
\hline
\end{tabular}

${ }^{*} \mathrm{p}<0.05$ 

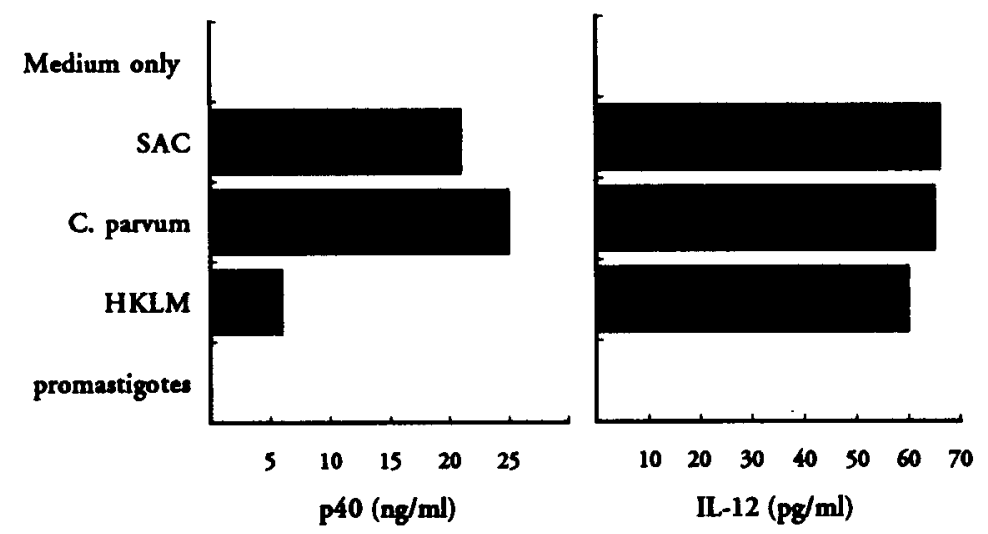

Fig. 1. L. major promastigotes fail to induce $\mathrm{p} 40$ or IL-12 production by macrophages cultured in vitro. Peritoneal macrophages from $\mathrm{C} 3 \mathrm{H}$ mice were cultured at $1 \times 10^{6} / \mathrm{ml} /$ well in 24-well plates. After $24 \mathrm{~h}$ incubation with S. aureus Cowan I strain (SAC) (0.001\%), C. parvum (10 $\mu \mathrm{g})$, L. monocytogenes (HKLM) $\left(10^{8}\right)$ or L. major metacyclic promastigotes $\left(10^{7}\right)$, supernatants were harvested and p40 and IL-12 measured. Data shown are from 1 of 3 representative experiments.

significant p40 or IL-12 was detectable in supernatants from these cultures. We failed to observe IL-12 production under several conditions, including different infection ratios, different sources of macrophages, and opsonization of the parasites with complement (data not shown). There are several possible explanations for the discrepancy between our in vivo and in vitro results. For example, the cells in the lymph node-producing IL-12 might not be macrophages, or the lymph node macrophages might differ in their responsiveness to $L$. major infection. Alternatively, undefined differences between the in vitro and in vivo conditions of infection might have an influence. To begin to address this issue, we investigated whether peritoneal macrophages infected in vivo would produce IL-12.

L. major metacyclic promastigotes $\left(5 \times 10^{7}\right)$ were inoculated into the peritoneal cavity and $24 \mathrm{~h}$ later the peritoneal cells were harvested. The cell population included approximately 50-60\% macrophages and $20 \%$ neutrophils; the remainder were lymphocytes, mast cells and eosinophils. The composition was similar following inoculation of phosphate-buffered saline (PBS). Approximately $25 \%$ of the macrophages contained an average of 2.5 parasites. Some cells were immediately tested for $\mathrm{p} 40$ production in an ELISPOT assay. Others were cultured in vitro for an additional $24 \mathrm{~h}$, after which the supernatant was collected and $\mathrm{p} 40$ and IL-12 measured. As seen in Fig. 2A, there was a dramatic increase in the number of peritoneal cells producing $\mathrm{p} 40$ after in vivo infection with $L$. major. As might be expected, following
$24 \mathrm{~h}$ of incubation, supernatants from these cells contained significantly more p 40 and IL-12 than control supernatants (Fig. 2B,C).

Taken together these data suggest that $L$. major promastigotes stimulate the production of IL-12 soon after infection in $\mathrm{C} 3 \mathrm{H}$ mice. Given the early IFN $\gamma$ and NK cytotoxic response observed in these animals, this might be expected [6]. However, our in vitro experiments, and those of others [9], indicate that $L$. major promastigotes fail to stimulate IL-12 production in vitro. It is possible that this inability may be an in vitro artifact, since following in vivo infection there was an increase in the number of cells producing p40 and an increase in the levels of both p40 and IL-12. Alternatively, it is possible that macrophages are not the source of IL-12 in vivo following L. major infection. However, although we have not yet identified the cells within the peritoneal cavity that are producing IL-12, we have found that IL-12 production is associated with the adherent population, implicating macrophages as the probable IL-12 source. In addition, in preliminary experiments we have found that peritoneal cells from scid mice also produce IL-12 following infection, ruling out $B$ cells as an IL-12 source (data not shown). Efforts in our laboratory are underway to confirm that macrophages are the IL- 12 producers in this infection.

The differences between the in vivo and in vitro infections that account for our results are unknown. Assuming that macrophages are the IL-12 producers in vivo, it is possible that accessory factors are pre- 
A.

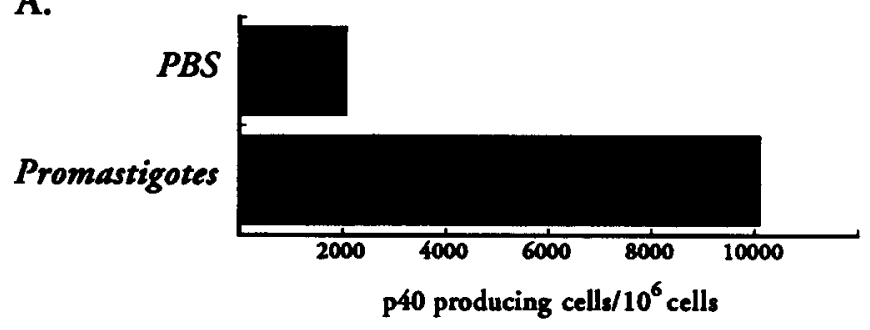

B.
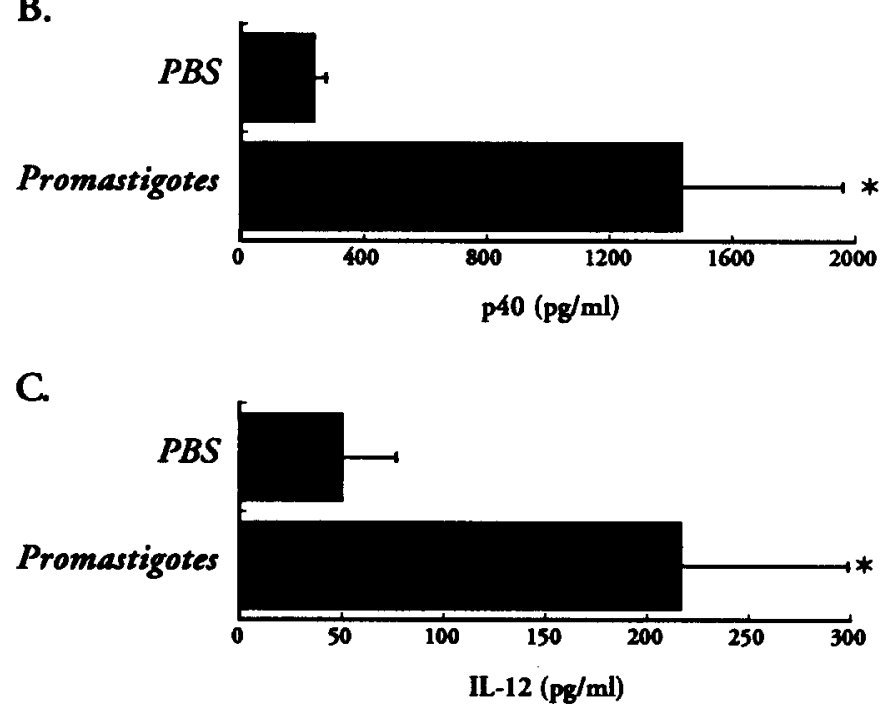

Fig. 2. L. major promastigotes induce p 40 and $1 \mathrm{~L}-12$ production by peritoneal cells infected in vivo. L. major $\left(5 \times 10^{7}\right)$ was injected into the peritoneal cavity of $\mathrm{C} 3 \mathrm{H}$ mice and the peritoneal cells harvested by lavage $24 \mathrm{~h}$ later. The number of cells producing p 40 was estimated by ELISPOT analysis immediately after harvesting from the peritoneal cavity (A). Cells were also incubated for an additional $24 \mathrm{~h}$ in vitro, and p40 (B) and IL-12 (C) measured in the supernatant. The ELISPOT results are representative of 3 experiments. The p40 and IL-12 levels represent the mean $\pm \mathrm{SE}$ of 10 or more experiments. "significance at $P<0.01$ using Student's $t$ test.

sent in vivo that are required for IL-12 production induced by $L$. major. Alternatively, a different form of the parasite may be inducing IL-12 in vivo. Leishmania enters the vertebrate host as a metacyclic promastigote which invades macrophages and transforms to an amastigote. Within the macrophage these amastigotes multiply, eventually rupture the cell, and re-invade other cells. It has been suggested that upon re-invasion amastigotes, rather than promastigotes, stimulate IL-12 production in vitro [9]. However, since relatively low numbers of parasites were present within macrophages following in vivo infection in the peritoneal cavity, it is unlikely that within $24 \mathrm{~h}$ amastigotes have ruptured macrophages and re-invaded other cells. A more likely explanation may involve the accumulation of a parasite-derived lipophosphoglycan (LPG) within the in vitro macrophage cultures. LPG is a molecule present on the surface of Leishmania promastigotes that helps anchor the parasite within the sandfly vector [10]. The molecule is secreted by the parasites when they are grown in culture and can be detected in vitro by immunofluorescence on the surface of both infected and non-infected macrophages (authors' unpublished observations). Interestingly, it has been reported that LPG is capable of inhibiting macrophage protein $\mathrm{ki}-$ nase C-mediated protein phosphorylation [11]. Following infection of macrophages in vitro a significant number of parasites remains extracellular and secretes LPG which accumulates in the culture. In contrast, it is less likely that LPG accumulates in high concentrations in the peritoneal cavity.

In summary, our data demonstrate that $L$. major infection is accompanied by enhanced production of IL-12. It has been reported that treatment of mice normally resistant to $L$. major with a polyclonal anti-IL-12 antisera enhances susceptibility [12] which we have recently confirmed using mAbs directed 
against IL-12. Taken together, these observations indicate that the increased IL-12 production observed in these mice may be critical both for the development of $\mathrm{CD}^{+}{ }^{+}$Th1 cells following L. major infection and for the development of resistance to infection.

\section{Acknowledgements}

This work was supported in part by grants from NIH (AI-30073, CA-20833, CA-09140) and the UNDP/World Bank/WHO Special Program for Research and Training in Tropical Diseases (TDR). L.Q.V. was partially supported by $\mathrm{CNPq}$, Brazil, on leave from the Department of Biochemistry and Immunology, UFMG, Brazil.

\section{References}

[1] Kobayashi, M., Fitz, L., Ryan, M., Hewick, R.M., Clark, S.C., Chan, S., Loudon, F., Sherman, B., Perussia, B. and Trinchieri, G. (1989) J. Exp. Med. 170, 827.

[2] Stern, A.S., Podlaski, F.J., Hulmes, J.D., Pan, Y.E., Quinn,
P.M., Wolitzky, A.G., Familletti, P.C., Stremlo, D.L., Truitt, T., Chizzonite, R. and Gately, M.K. (1990) Proc. Natl. Acad. Sci. USA 87, 6808 .

[3] Manetti, R., Parronchi, P., Giudizi, M.G., Piccinni, M.-P., Maggi, E., Trinchieri, G. and Romagnani, S. (1993) J. Exp. Med. 177, 1199.

[4] Hsieh, C.-S., Macatonia, S.E., Tripp, C.S., Wolf, S.F., O’Garra, A., and Murphy, K.M. (1993) Science 260, 547.

[5] Afonso, L.C.C., Scharton, T.M., Vieira, L.Q., Wysocka, M., Trinchieri, G. and Scott, P. (1994) Science 263, 235.

[6] Scharton, T.M. and Scott, P. (1993) J. Exp. Med. 178, 567.

[7] D'Andrea, A., Rengaraju, M., Valiante, N.M., Chehimi, J., Kubin, M., Aste, M., Chan, S.H., Kobayashi, M., Young, D., Nickbarg, E., Wolf, S.F., and Trinchieri, G. (1992) J. Exp. Med. 176, 1387.

[8] Morris, S.C., Madden, K.B., Adamovicz, J.J., Gause, W.C., Hubbard, B.R., Gately, M.K. and Finkelman, F.D. (1994) J. Immunol. 152, 1047.

[9] Reiner, S.L., Zheng, S., Wang, Z.-E., Stowring, L. and Locksley, R.M. (1994) J. Exp. Med. 179, 447.

[10] Turco, S.J. and Descoteaux, A. (1992) Annu. Rev. Microbiol. 46,65 .

[11] Descoteaux, A., Matlashewski, G. and Turco, S.J. (1992) J. Immunol. 149, 3008 .

[12] Sypek, J.P., Chung, C.L., Mayor, S.E.H., Subramanyam J.M., Goldman, S.J., Sieburth, D.S., Wolf, S.F. and Schaub, R.G. (1993) J. Exp. Med. 177, 1797. 